\title{
Inhibitive properties of some chelates and their ligands in acid corrosion of zinc
}

\author{
V. P. Grigor'ev, ${ }^{1}$ N. A. Belousova, ${ }^{1}$ E. V. Plekhanova ${ }^{1}$ \\ and A.S. Burlov ${ }^{2}$ \\ ${ }^{1}$ Southern Federal University, ul. Zorge 7, Rostov-on-Don, \\ 344090 Russian Federation \\ ${ }^{2}$ Research Institute of Physical and Organic Chemistry at Southern Federal University, \\ pr. Stachki 94/3, Rostov-on-Don, 344104 Russian Federation
}

E-mail: valentgrig@mail.ru

\begin{abstract}
A comparative study of the protective properties of zinc chelate complexes with various $o$ hydroxyazomethine derivatives having substituents of various nature at the ligand benzene ring has been carried out for zinc acid corrosion in $\mathrm{H}_{2} \mathrm{SO}_{4}$ solutions.
\end{abstract}

Key words: corrosion, inhibitor, chelates, ligands, zinc.

Received: June 26, 2014.

doi: $10.17675 / 2305-6894-2014-3-3-204-214$

The corrosion resistance of zinc in acidic media is quite low. The most popular methods of metal protection from corrosion in aqueous media include inhibition of the corrosive medium and electrochemical methods based on the negative difference effect upon imposition of cathodic polarization on the corroding metal. Implementation of these methods with high-efficiency prevention of acid corrosion of zinc encounters serious difficulties. To protect zinc, it is most reasonable to use cationic inhibitors that bear a positive charge and hence readily undergo electrostatic adsorption on a zinc electrode surface in an acid solution. Normally, a molecule of a cationic inhibitor contains $\mathrm{N}^{3-}$ nitrogen that is readily protonated to give an $\mathrm{R}_{-} \mathrm{NH}_{3}^{+}$group. The latter is readily discharged to produce hydrogen and thus catalyzes the slow discharge reaction. Thus, a cationic inhibitor can slow down corrosion considerably if its screening effect dominates over its catalytic effect. The efficiency of zinc protection by cathodic polarization is low. The high rate of zinc spontaneous dissolution would require high-density external cathodic current to be applied since the polarizability of zinc is low. Application of such cathodic current densities would result in enhanced hydrogen evolution that is quite dangerous, as well as a large consumption of external polarizing current.

In view of the above, the feasibility of zinc protection from acid corrosion by insoluble inner-complex compounds, namely, $\mathrm{Zn}$ chelates, is of certain interest. The specific features of metal corrosion in the presence of oxyazomethine have been studied 
thoroughly [1-5]. The feasibility of corrosion inhibition by chelates of these metals has not been studied.

\section{Experimental procedure}

Corrosion and polarization measurements were carried out in $0.5 \mathrm{M} \mathrm{H}_{2} \mathrm{SO}_{4}$ as the corrosive medium. The concentration of inhibiting additives was varied from $0.063 \cdot 10^{-2} \mathrm{~mol} / 1$ to $1 \cdot 10^{-2} \mathrm{~mol} / \mathrm{l}$.

Prior to corrosion tests, zinc specimens with $2 \mathrm{~cm}^{2}$ surface area were polished and degreased with ethanol. After degreasing, the specimens were thoroughly washed with flowing distilled water, then dried with filter paper.

Prepared specimens were weighed on a VLR-200 balance to within $\pm 0.00005 \mathrm{~g}$, then immersed in test tubes with the corrosive solutions.

The corrosion rate was determined from the mass loss:

$$
j=\frac{\Delta m}{S \cdot t}
$$

where $\Delta m$ is the decrease in specimen mass, $\mathrm{g}$; $S$ is the specimen surface area, $\mathrm{m}^{2}$; and $t$ is the time of specimen exposure in the solution, hours.

The protective effect of inhibitors was estimated by the inhibition coefficient:

$$
K=\frac{j_{0}}{j_{i}}
$$

and the degree of protection:

$$
Z=\frac{j_{0}-j_{i}}{j_{0}}
$$

where $j_{0}$ is the corrosion rate of a specimen in a solution containing no inhibitor and $j_{i}$ is the corrosion rate of a specimen in an inhibited solution.

Polarization measurements were carried out using the galvanostatic method. The tests were performed in hydrogen atmosphere; hydrogen was passed for $20 \mathrm{~min}$. The cell was thermostated at $20^{\circ} \mathrm{C}$. A silver chloride electrode was used as the reference electrode.

\section{Measurement results and discussion}

This study was carried out using chelates with o-hydroxyazomethine ligands as inhibitors:

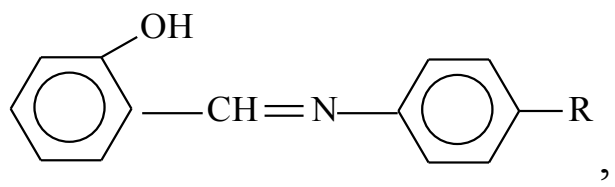

where $\mathrm{R}=\mathrm{H}, \mathrm{CH}_{3}$, or $\mathrm{OCH}_{3}$. 
The chelate node in the corresponding zinc chelate has the form:

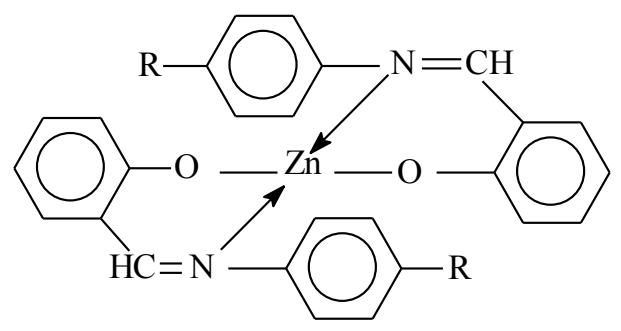

Let us designate the chelate with $\mathrm{R}=\mathrm{H}$ as number 1 , that with $\mathrm{R}=\mathrm{CH}_{3}$ and $\mathrm{R}=$ $\mathrm{OCH}_{3}$ as numbers 2 and 3 , respectively.

Chelates 1-3 were obtained by chemical synthesis, i.e., by combining equal volumes of methanolic solutions of zinc acetate $\left(\mathrm{CH}_{3} \mathrm{COO}\right)_{2} \mathrm{Zn}$ and an o-hydroxymethine ligand. The reaction

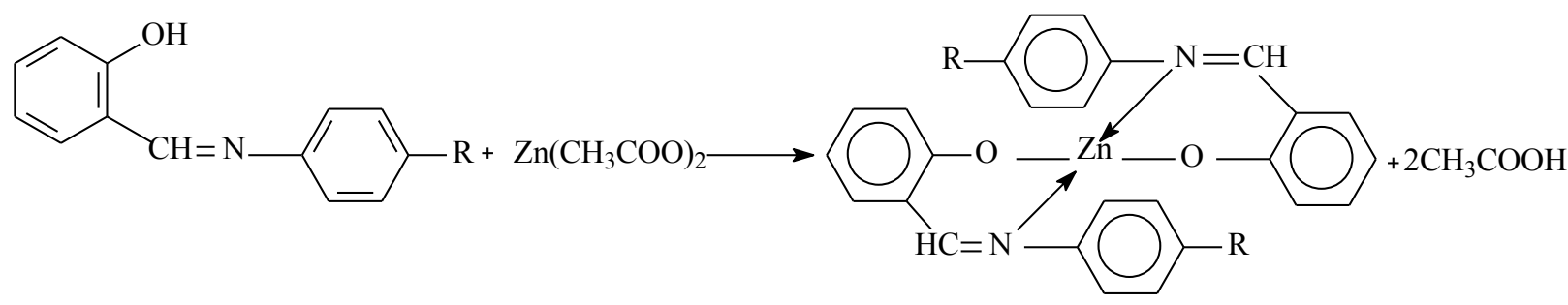

gives a hardly soluble chelate that forms a precipitate. Attempts to obtain this chelate by addition of a ligand to an acid solution containing zinc salts failed and no chelate was formed. In this case, the azomethine molecule can decompose into components that can also act as adsorption inhibitors:
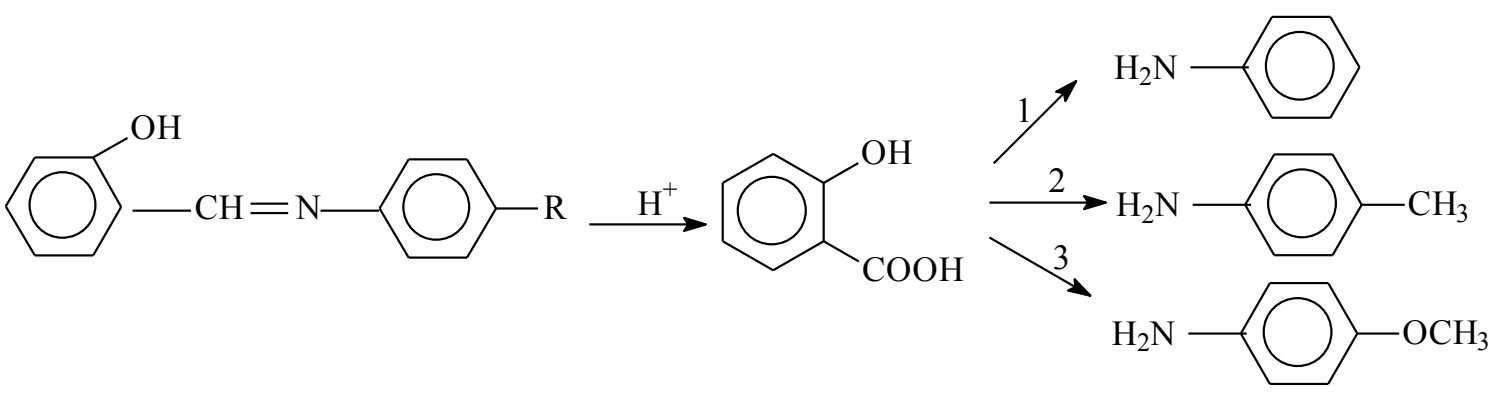

where (1) is aniline, (2) is toluidine, and (3) is anisidine.

Chelates can ensure reliable protection of zinc only provided that chelates formed on the surface are firmly attached to the electrode surface and thus ensure its protection by the blocking mechanism.

Below we present the dependence of the coefficients of zinc inhibition in $0.5 \mathrm{M}$ $\mathrm{H}_{2} \mathrm{SO}_{4}$ by the possible participants of the corrosion process in the presence of chelates, ligands and their corresponding structural components as functions of their volume concentrations. 
Table 1. Dependence of $\mathrm{Zn}$ corrosion inhibition coefficients in $0.5 \mathrm{M} \mathrm{H}_{2} \mathrm{SO}_{4}$ on the concentration of certain zinc chelates, their ligands, and ligand fragments at $t=21^{\circ} \mathrm{C}(\mathrm{R}=\mathrm{H})$.

\begin{tabular}{ccccccc}
\hline Compound & \multicolumn{2}{c}{ Chelate complex 1 } & \multicolumn{2}{c}{ Ligand 1 } & \multicolumn{2}{c}{ Aniline } \\
\hline $\mathbf{C}, \mathbf{~ m o l} / \mathbf{l}$ & $\boldsymbol{K}$ & $\boldsymbol{Z}, \boldsymbol{\%}$ & $\boldsymbol{K}$ & $\boldsymbol{Z}, \mathbf{\%}$ & $\boldsymbol{K}$ & $\boldsymbol{Z}, \boldsymbol{\%}$ \\
\hline $1 \cdot 10^{-2}$ & 302.6 & 99.8 & 60.05 & 98 & 1.85 & 45 \\
$0.5 \cdot 10^{-2}$ & 104.7 & 98.9 & 12.3 & 92 & 1.82 & 45 \\
$0.25 \cdot 10^{-2}$ & 74 & 98.2 & 5.6 & 83 & 1.53 & 35 \\
$0.125 \cdot 10^{-2}$ & 39.1 & 97.9 & 3.6 & 72 & 1.50 & 34 \\
$0.063 \cdot 10^{-2}$ & 8.3 & 87.8 & 1.5 & 34 & 1.45 & 31 \\
\hline
\end{tabular}

Table 2. Dependence of $\mathrm{Zn}$ corrosion inhibition coefficients in $0.5 \mathrm{M} \mathrm{H}_{2} \mathrm{SO}_{4}$ on the concentration of certain zinc chelates, their ligands, and ligand fragments at $t=21^{\circ} \mathrm{C}\left(\mathrm{R}=\mathrm{CH}_{3}\right)$.

\begin{tabular}{ccccccc}
\hline Compound & \multicolumn{2}{c}{ Chelate complex 2 } & \multicolumn{2}{c}{ Ligand 2 } & \multicolumn{2}{c}{ Toluidine } \\
\hline $\mathbf{C}, \mathbf{~ m o l} / \mathbf{l}$ & $\boldsymbol{K}$ & $\boldsymbol{Z}, \mathbf{\%}$ & $\boldsymbol{K}$ & $\boldsymbol{Z}, \boldsymbol{\%}$ & $\boldsymbol{K}$ & $\boldsymbol{Z}, \boldsymbol{\%}$ \\
\hline $1 \cdot 10^{-2}$ & 180.9 & 99.4 & 58.4 & 99 & 2.12 & 53 \\
$0.5 \cdot 10^{-2}$ & 168.9 & 99.3 & 22.2 & 96 & 1.64 & 40 \\
$0.25 \cdot 10^{-2}$ & 76.3 & 98.7 & 4.6 & 78 & 1.36 & 27 \\
$0.125 \cdot 10^{-2}$ & 24.8 & 69.0 & 3.4 & 71 & 1.33 & 25 \\
$0.063 \cdot 10^{-2}$ & 7.9 & 87.7 & 1.03 & 5 & 1.20 & 16 \\
\hline
\end{tabular}

As follows from Tables 1 and 2, all the chelate compounds studied and their components have protective properties towards acid corrosion of zinc. However, a number of considerable differences between them should be noted:

- In a series of corresponding compounds: chelate - ligand - benzene derivatives, a decrease in inhibition coefficient $K$ is observed in all cases;

- The inhibition coefficients of chelate compounds, e.g., at a concentration of $1 \cdot 10^{-2}$ $\mathrm{mol} / \mathrm{l}$, are dozens times higher than those of the corresponding ligands. A similar picture is also observed at the other concentrations of chelates 1 and 2;

- The $K$ and $Z$ values of the ligands are generally higher than the possible corresponding decomposition products in acidic medium, i.e., aniline and toluidine (Tables 1 and 2).

This comparative analysis of the data from Tables 1 and 2 indicates unambiguously that chelates and ligands in acidic media retain the specific features of their chemical structures formed upon synthesis in methanolic solutions and can therefore be recommended as more efficient corrosion inhibitors than their ligands, and especially than the possible decomposition products of the latter. This is also confirmed by the data in 
Table 4 for ligand 3 when compared with the data from Tables 1 and 2, i.e., its $K$ and $Z$ values are generally higher than those of the corresponding aniline derivatives.

Table 3. Dependence of inhibition coefficients of zinc corrosion in $0.5 \mathrm{M} \mathrm{H}_{2} \mathrm{SO}_{4}$ on the concentration of ligand 3 at $t=21^{\circ} \mathrm{C}\left(\mathrm{R}=\mathrm{CH}_{3}\right)$.

\begin{tabular}{ccc}
\hline Compound & \multicolumn{2}{c}{ Ligand 3 } \\
\hline $\mathbf{C}, \mathbf{~ m o l} / \mathbf{l}$ & $\boldsymbol{K}$ & $\boldsymbol{Z}, \boldsymbol{\%}$ \\
\hline $1 \cdot 10^{-2}$ & 55.95 & 98 \\
$0.5 \cdot 10^{-2}$ & 17.7 & 94 \\
$0.25 \cdot 10^{-2}$ & 75 & 86 \\
$0.125 \cdot 10^{-2}$ & 2.5 & 58 \\
$0.063 \cdot 10^{-2}$ & 1.3 & 24 \\
\hline
\end{tabular}

The results of corrosion measurements with all the compounds that noticeably inhibit zinc corrosion (chelates and ligands) plotted in logarithmic coordinates give linear plots:

$$
\lg K=a+b \lg C,
$$

where $a$ and $b$ are constants determined by the nature of the compound studied, Figs. 1, 2 .

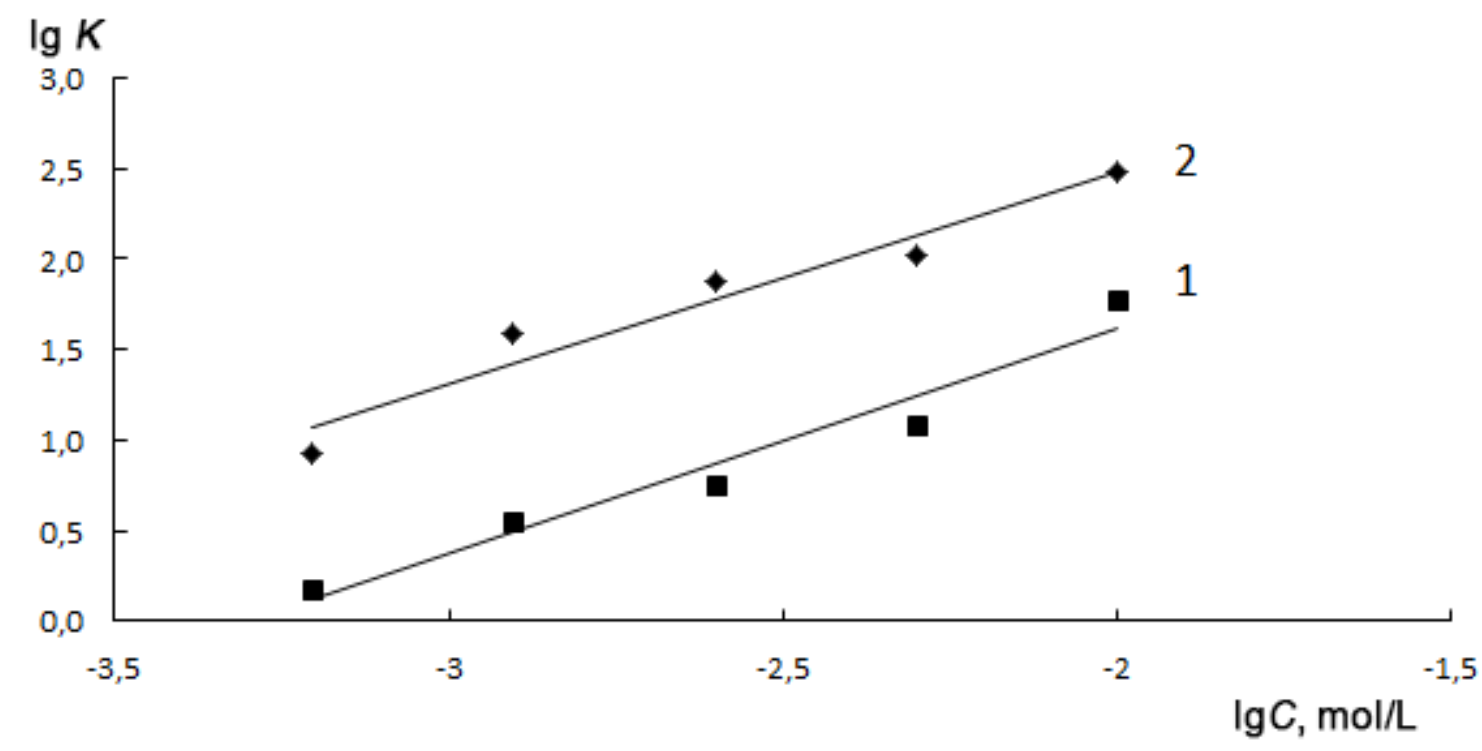

Figure 1. Logarithmic plot of inhibition coefficient on concentration for: 1, ligand 1;2, chelate 1. 


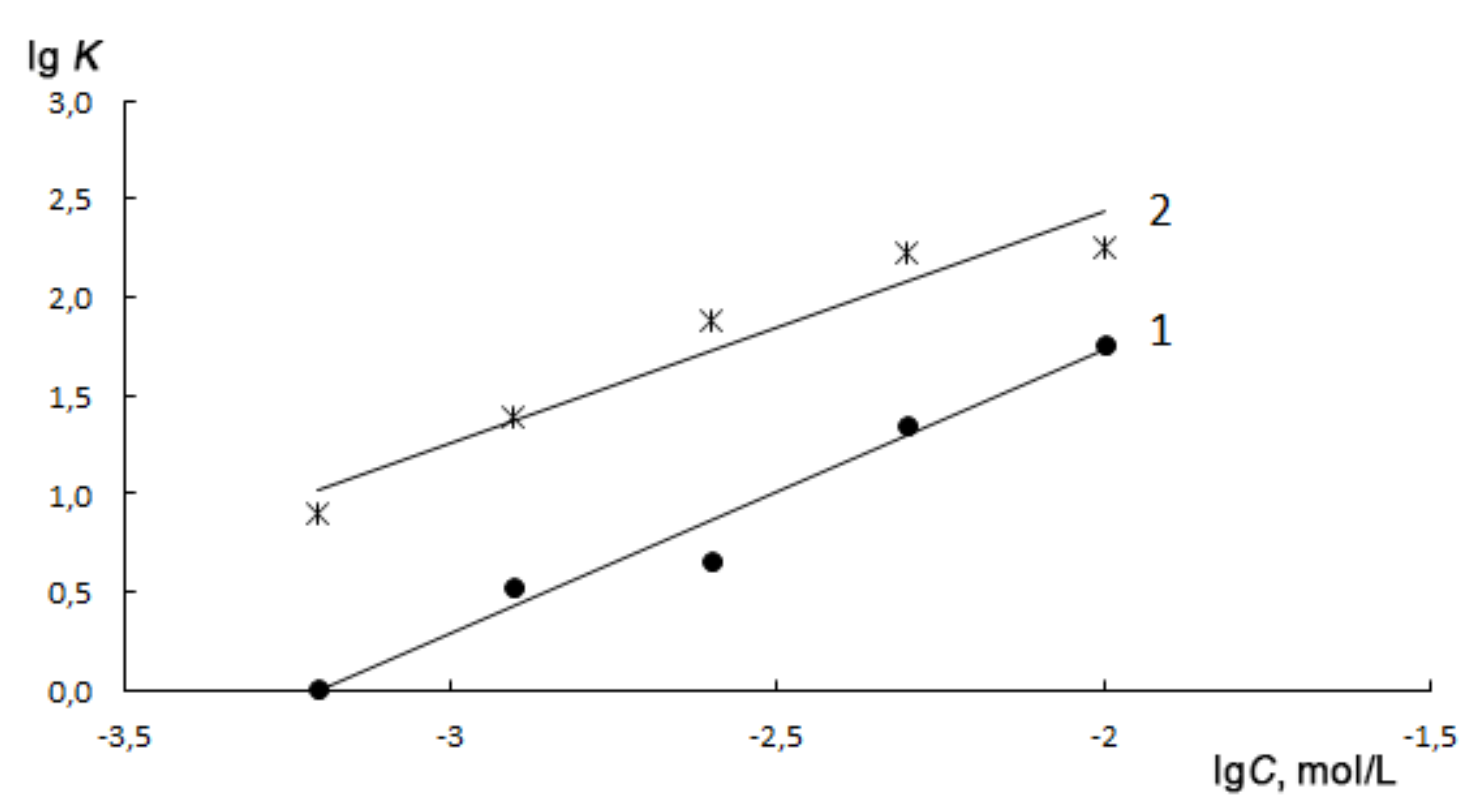

Figure 2. Logarithmic plot of inhibition coefficient on concentration for: 1, ligand 2; 2, chelate 2.

The form of equation (1) indicates a clearly adsorptive character of protection both by chelates $\mathbf{1}$ and $\mathbf{2}$ and by the corresponding ligands, i.e., non-substituted and methylsubstituted $o$-hydroxyazomethine, as inhibitors.

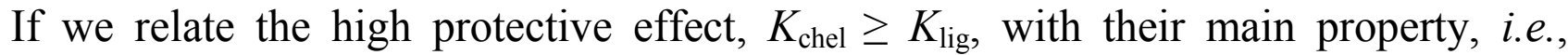
formation of poorly soluble chelates on zinc electrode surface, it can be expected that a gradual increase in chelate concentration would increase the inhibition coefficient to a certain level where critical shielding of the surface with the adsorbed poorly soluble chelate is reached. A subsequent increase in the concentration should result in adsorption passivation of the electrode. Apparently, these chelate concentrations are not reached under the conditions of our experiment.

The high inhibiting effect of chelates in comparison with ligands can primarily be explained by their larger molecule size. Furthermore, this enlargement increases the number of possible adsorption sites significantly (the number of unsaturated bonds increases). It is also possible that the bond of the chelate molecule with the metal surface would strengthen due to a partial alteration of the chelate node. Apparently, chelates can be formed on the surface of a $\mathrm{Zn}$ electrode due to interaction of adsorbed inhibitor molecules (which subsequently become ligands) with surface $\mathrm{Zn}^{2+}$ ions that are part of the zinc crystal lattice: 


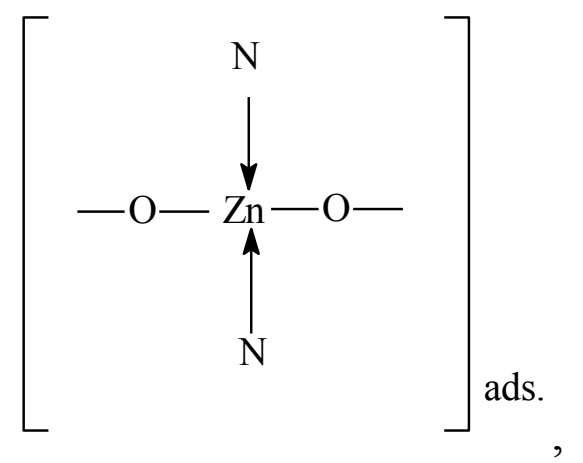

which is typical of normal chelate molecules. In such case, the bond would be much stronger and renewal of the dissolving zinc surface much slower, which inevitably results in an increase in $K$. It is known from numerous studies that the more nucleophilic the substituent $\mathrm{R}$ in a molecule of a compound in a reaction series, the higher the inhibiting effect. In fact, in the case of compounds 1-3 where $\mathrm{R}=-\mathrm{H},-\mathrm{CH}_{3}$ and $-\mathrm{OCH}_{3}$, respectively, the Hammett constants are $\sigma_{\mathrm{H}}=0, \sigma_{\mathrm{CH}_{3}}=-0.17$, and $\sigma_{\mathrm{OCH}_{3}}=-0.268$, the $b$ coefficients in Equation (1) are 1.15, 1.49 and 2.09, respectively. For chelates with $\mathrm{R}=\mathrm{H}$ and $\mathrm{CH}_{3}$, the $b$ coefficients in Equation (1) are 0.8 and 1.5, respectively.

Polarization measurements were carried out at four temperatures: 15, 20, 25, and $30^{\circ} \mathrm{C}$. Cathodic and anodic polarization of zinc electrode in $0.5 \mathrm{M} \mathrm{H}_{2} \mathrm{SO}_{4}$ is insignificant in the current density range studied. The anodic potential shifts by $0.07 \mathrm{~V}$ in the positive direction from the free corrosion potential of zinc $\left(i_{\text {polar }}=0\right), E \sim-0.69 \mathrm{~V}$ at $15^{\circ} \mathrm{C}$ (Fig. 3).

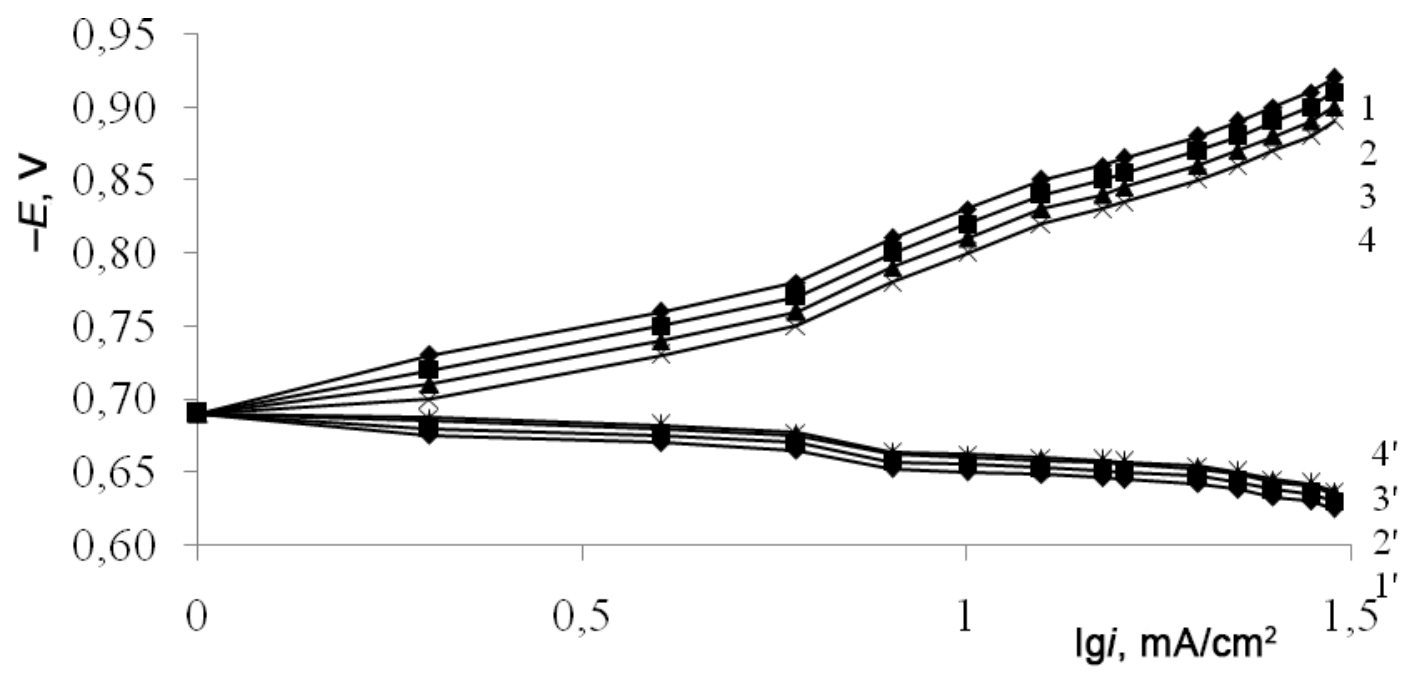

Figure 3. Cathodic and anodic polarization curves for zinc in $0.5 \mathrm{M}$ sulfuric acid (background) at temperatures: $1,1^{\prime}-15^{\circ} \mathrm{C} ; 2,2^{\prime}-20^{\circ} \mathrm{C} ; 3,3^{\prime}-25^{\circ} \mathrm{C} ; 4,4^{\prime}-30^{\circ} \mathrm{C}$.

An increase in temperature to $30^{\circ} \mathrm{C}$ accelerates the anodic process. The potential at the same current density shifts by $0.04 \mathrm{~V}$ in the positive direction. An increase in temperature shifts the anodic polarization curves insignificantly. The observed larger slope of the cathodic curves indicates its higher polarizability. Imposing a cathodic current of $i=$ 
$30 \mathrm{~mA} / \mathrm{cm}^{2}$ shifts the $E$ from the free corrosion potential to $E=-0.93 \mathrm{~V}$. An increase in temperature accelerates the cathodic process to some extent.

We performed polarization measurements in $0.5 \mathrm{M}$ sulfuric acid with addition of aniline, toluidine, or salicylic aldehyde. The current versus potential plots in the presence of these additives have similar shapes. The changes of electrode polarizability in the presence of these additives are insignificant, or not observed at all in some cases. For example, in comparison with the background solution, addition of aniline nearly did not affect the anodic reaction but slightly accelerated the cathodic one (Fig. 4).

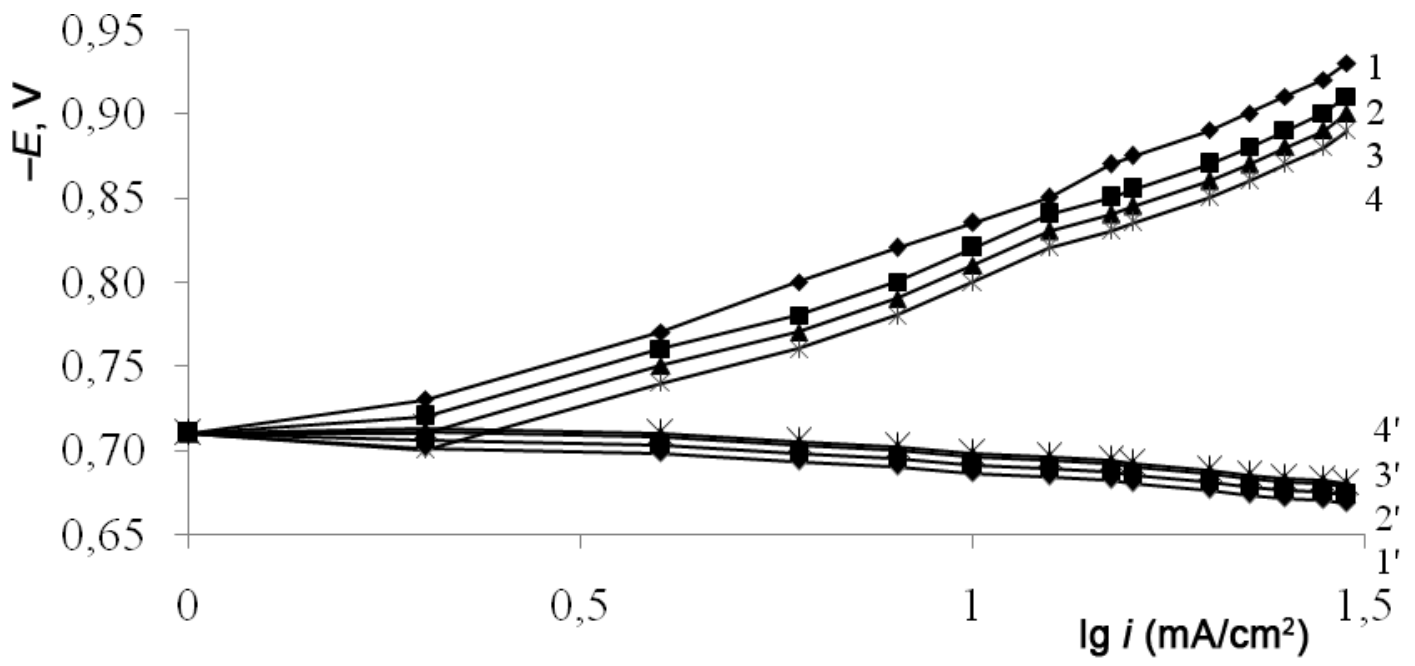

Figure 4. Cathodic and anodic polarization curves for zinc in $0.5 \mathrm{M}$ sulfuric acid (aniline) at temperatures: $1,1^{\prime}-15^{\circ} \mathrm{C} ; 2,2^{\prime}-20^{\circ} \mathrm{C} ; 3,3^{\prime}-25^{\circ} \mathrm{C} ; 4,4^{\prime}-30^{\circ} \mathrm{C}$.

Addition of toluidine does not affect the anodic process, either, but slows down somewhat the cathodic process. The insignificant effect of aniline and toluidine explains the low inhibitive effect of these compounds on zinc corrosion.

Polarization measurements in the presence of ligands $\mathbf{1}$ and $\mathbf{2}$ showed a picture that differed strongly from that for aniline derivatives (Fig. 5).

The polarization curves in the presence of the ligands mentioned above are characterized by an abrupt increase in cathodic polarization. In the background solution at a current density of $i=30 \mathrm{~mA} / \mathrm{cm}^{2}$, the free corrosion potential shifted by $\Delta E \sim 0.22 \mathrm{~V}$, whereas this value amounted to $\Delta E \sim 0.55 \mathrm{~V}$ on average in the presence of ligands $1-3$. In other words, cathodic polarization increases more than twofold in the presence of ligands 1-3 in comparison with the background solution. The latter fact shows that these ligands are cathodic inhibitors.

The inhibition coefficients corresponding to these compounds are dozens times larger than those for aniline and salicylic aldehyde derivatives. This indicates that it is difficult to expect a noticeable decomposition of these ligands into the corresponding fragments upon dissolution. Unlike cathodic polarization curves in the presence of ligands, anodic curves nearly do not change shape in comparison with the background solution, which indicates that they do not noticeably affect the anodic process. 


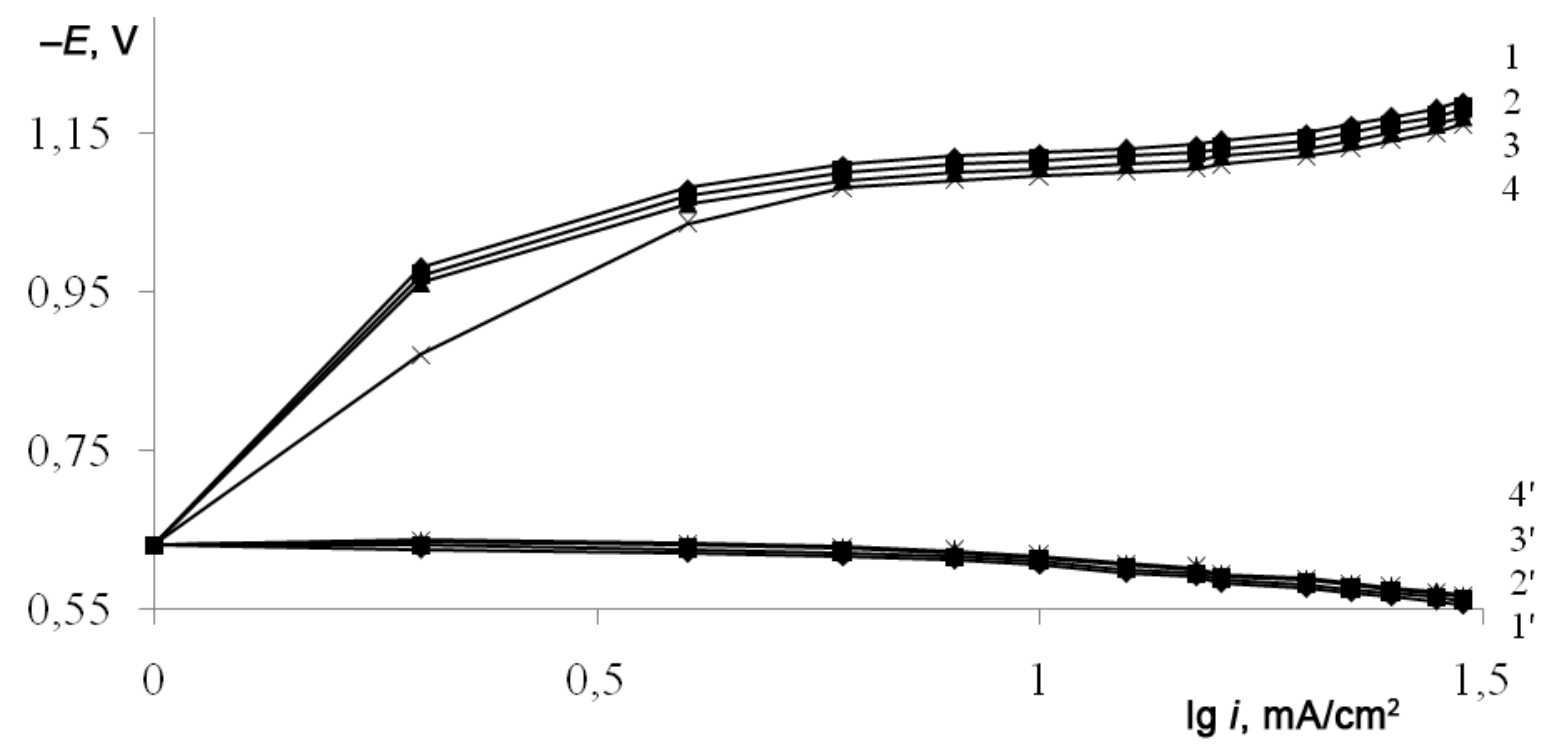

Figure 5. Cathodic and anodic polarization curves for zinc in $0.5 \mathrm{M}$ sulfuric acid (ligand 1) at temperatures: $1,1^{\prime}-15^{\circ} \mathrm{C} ; 2,2^{\prime}-20^{\circ} \mathrm{C} ; 3,3^{\prime}-25^{\circ} \mathrm{C} ; 4,4^{\prime}-30^{\circ} \mathrm{C}$.

Cathodic and anodic polarization curves for $0.5 \mathrm{M}$ sulfuric acid with addition of chelates $\mathbf{1}$ and $\mathbf{2}$ are similar in appearance to the corresponding curves for ligands $\mathbf{1}$ and $\mathbf{2}$. Like in the latter case, the shapes of anodic polarization curves are similar to those recorded in the reference solution (Fig. 6).

An abrupt negative shift of the electrode potential is observed for cathodic curves. Some parts of these curves contain shelves and areas whose shapes resemble limiting currents. Thus, both the ligands and the chelates on their basis have similar polarization characteristics.

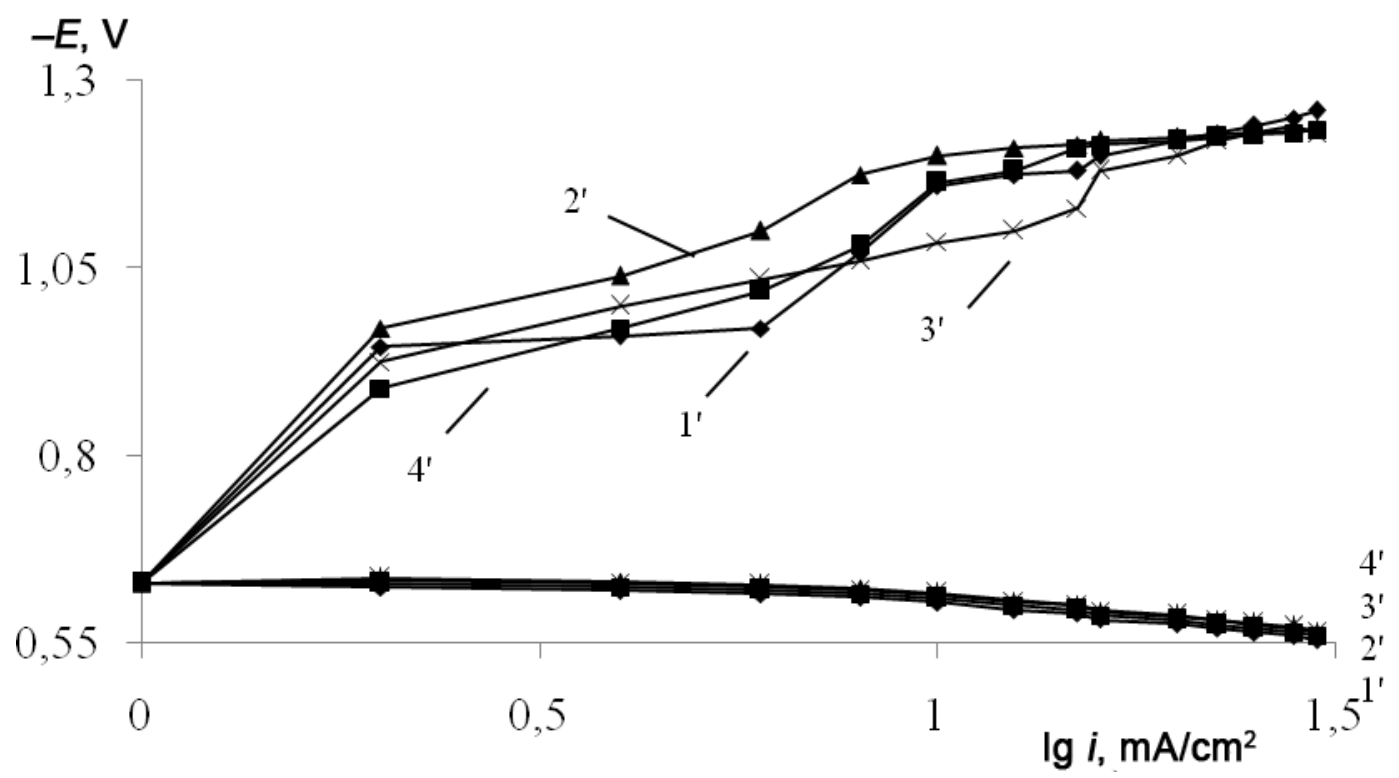

Figure 6. Cathodic and anodic polarization curves for zinc in $0.5 \mathrm{M}$ sulfuric acid (chelate 1) at temperatures: $1,1^{\prime}-15^{\circ} \mathrm{C} ; 2,2^{\prime}-20^{\circ} \mathrm{C} ; 3,3^{\prime}-25^{\circ} \mathrm{C} ; 4,4^{\prime}-30^{\circ} \mathrm{C}$. 
It is well known that the value of effective activation energy of corrosion $W$ makes it possible to judge on the process which controls the process. The $W$ value was determined from the temperature plot of the corrosion rate using the Arrhenius equation. The values obtained are shown in Fig. 7.

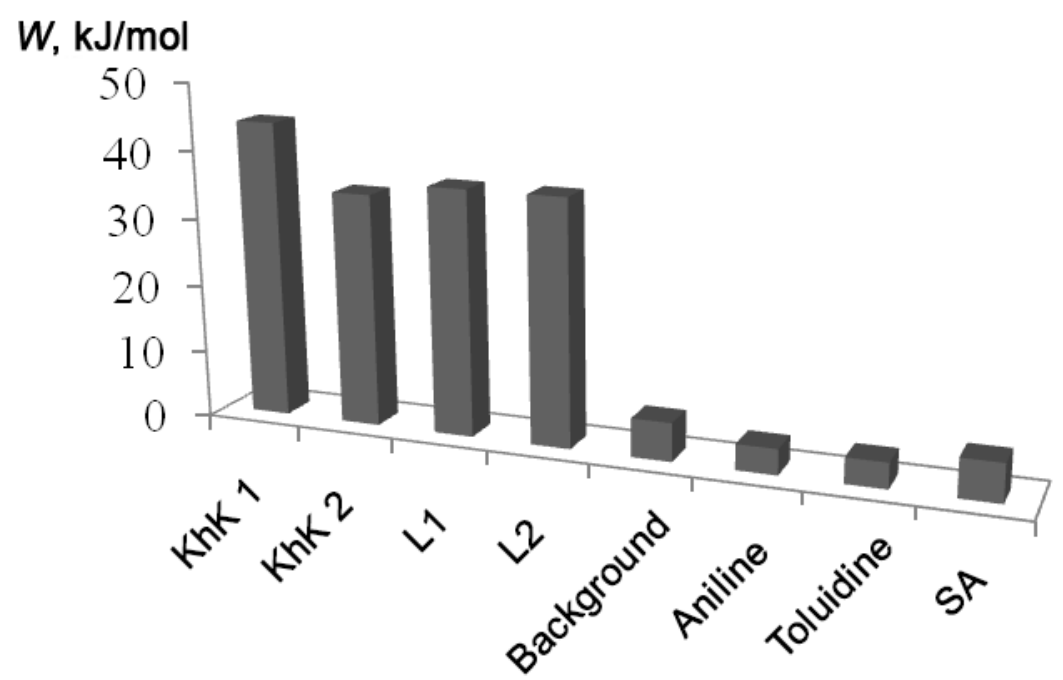

Figure 7. The effective activation energies of zinc corrosion in the background solution and in the presence of various additives $(\mathrm{SA}=$ salicylic aldehyde).

Zinc corrosion in non-inhibited acid is characterized by diffusion control. Addition of salicylic aldehyde, aniline, or toluidine decreases somewhat the $W$ values without changing the type of control. Addition of ligands and chelates based on them results in an abrupt increase in effective activation energy of corrosion and the process switches to activation control.

\section{Conclusions}

1. A first comparative study of the corrosion behavior of zinc in $0.5 \mathrm{M}$ sulfuric acid in the presence of zinc-based chelate compounds and $o$-hydroxyazomethine has been carried out. It has been shown that these chelate complexes are efficient inhibitors of zinc corrosion and that their efficiency is higher than that of the corresponding ligands. The possible decomposition products of the ligands used in acidic medium have much lower anti-corrosion activity.

2. A study of the concentration dependences of corrosion inhibition coefficients in the presence of chelate complexes has shown that they are described by $\lg K-\lg c \operatorname{linear}$ relationships. The latter corresponds to the adsorption mechanism of corrosion inhibition by these compounds.

3. The zinc chelate compounds studied and the corresponding ligands hinder the cathodic reaction during zinc corrosion considerably but do not have a strong effect on the anodic process. 
4. The effective activation energies of corrosion that we obtained indicate that the process occurs under diffusion control in the background solution and in the presence of the possible decomposition products of the ligands studied. Addition of ligands or chelates on their basis changes the corrosion process from diffusion control to activation control.

\section{References}

1. V. P. Grigor'ev, S. P. Shpan'ko and O. V. Dymnikova, Zashch. met., 2000, 36, no. 4, 420 (in Russian).

2. V. P. Grigor'ev, S. P. Shpan'ko and A. S. Nassar, Zashch. met., 2000, 36, no. 5, 525 (in Russian).

3. V. P. Grigor'ev, S. P. Shpan'ko, A. S. Nassar and O. V. Dymnikova, Elektrokhimiya, 2000, 36, no. 10, 1306 (in Russian).

4. V. P. Grigor'ev, E. V. Plekhanoa, S. P. Shpan'ko and V. V. Boginskaya, Fizikokhimiya poverkhnosti i zashchita metallov, 2010, no. 1, 88 (in Russian).

5. V. P. Grigor'ev, E. V. Plekhanova, S. P. Shpan'ko and A. S. Burlov, Korroz.: Mater. Zashch., 2012, no. 10, 18 (in Russian). 